\title{
Uma breve introdução à subcultura cyberpunk. Estilo, alteridade, transformações e hibridismo na cibercultura ${ }^{1}$
}

\author{
Adriana Amaral2 \\ Universidade Tuiuti do Paraná \\ adriamaral@yahoo.com
}

\begin{abstract}
Resumo: Esse paper tem como objetivo fazer uma breve apresentação e discussão a respeito dos conceitos de subcultura enquanto uma das forças constituintes do conceito de cyberpunk. Através de um resgate sociológico da influência de suas principais tendências juvenis desde o pós-guerra do século 20 até o início do século 21 apresenta-se uma das formações estéticas da cibercultura. Nesse contexto, escolhemos como objeto da hibridização das mesmas, o cyberpunk, analisado aqui como "estilo de vida".
\end{abstract}

Résumé: L'objectif principal de cet article est de commencer une brève discussion et présentation au sujet des concepts de subculture en tant qu'un des forces constitutives derrière le concept de Cyberpunk elle-même. Dans toute une histoire sociologique de l'influence de ses tendances plus importantes dans la jeunesse, du d'après-guerre au 2oème siècle à begginning du 21ème siècle, la subculture est une formacion très important de la base aesthetical de la cyberculture. Dans ce contexte, nous avons choisi le Cyberpunk comme exemple de hybridism entre elles pendant qu'il est analysé ici comme style de vie.

Abstract: The main objective of this paper is to start a brief discussion and presentation about subculture concepts as one of the constitutive forces behind cyberpunk concept itself. Throughout a sociological history of the influence of its most important trends in youth, from the post-war in the 2oth century to the begginning of 21st century, subculture is one of the aesthtical basis of cyberculture. In this context, we have chosen cyberpunk as an example of hybridism between them as it is analyzed here as a life style.

Resumen: El objetivo principal de este papel es comenzar una breve discusión y la presentación sobre conceptos del subcultura como una de las fuerzas constitutivas detrás del concepto del Cyberpunk. A través de una historia sociológica de la influencia de sus tendencias más importantes de la juventud, del de la posguerra en el vigésimo siglo al comenzó del siglo XXI, el

\footnotetext{
${ }^{1}$ Essa pesquisa traz algumas questões e observações apresentadas na tese de doutorado da autora, intitulada Visões Perigosas: uma arque-genealogia do cyberpunk - do romantismo gótico às subculturas. Comunicação e cibercultura em Philip K. Dick defendida em julho de 2005. O presente trabalho foi realizado com o apoio do CNPq, uma entidade do Governo Brasileiro voltado ao Desenvolvimento Científico e Tecnológico através do Estágio de Doutorado (Bolsa Sanduíche), no Boston College, Boston, EUA, set.2004 a fev.2005.

2 Doutora em Comunicação Social pela PUCRS e Professora do Programa de Mestrado em Comunicação e Linguagens da Universidade Tuiuti Paranaense.
} 
subcultura es uno de la base estetica de la cibercultura. En este contexto, hemos elegido Cyberpunk como ejemplo del hybridism entre ellas mientras que se analiza aquí como estilo de vida.

Palavras-chave: subcultura, cibercultura, cyberpunk, estilo

Mots-clé: cyberculture, subculture, cyberpunk, style.

Keywords: subculture, cyberculture, cyberpunk, style

Palabras clave: cibercultura, subcultura, ciberpunk, estilo.

O papel das subculturas3 é da ordem da formação de um "capital subcultural", conforme diz Thornton (1996), sendo constituídas por jovens que negociam status e poder dentro de seus mundos próprios, atores sociais no teatro da contemplação do mundo. A partir da própria formação do conceito de subcultura já podemos compreendê-la dentro das relações com a cultura e a sociedade.

De fato, o prefixo 'sub', que remete a uma categoria mais baixa ou secundária em relação à entidade que ela modifica, nos dá uma pista para uma das pressuposições principais dessa tradição de pesquisa - ou seja, que os grupos sociais investigados em nome das 'subculturas' estão subordinados, subalternos ou são subterrâneos4 (GELDER e THORNTON, 1997, p. 04).

\section{Notas introdutórias sobre a questão das subculturas.}

Não existe um único conceito de subcultura, e também ele se modificou ao longo do tempo e vêm sendo muito discutido, principalmente, a partir da perspectiva dos estudos culturais do CCCS - Centre for Contemporary Cultural Studies - da Escola de Birmingham no final dos anos 70, nunca tendo perdido suas relações entre cultura, comunidade, massas e sociedade

\footnotetext{
$3 \mathrm{O}$ termo foi criado nos anos 40 a partir da influência sociológica da Escola de Chicago, embora seu uso mais corrente tenha se amplificado nos anos 60.

4 "In fact, the prefix 'sub', which ascribes a lower or secondary rank to the entity it modifies, give us a clue to one of the main assumptions of this tradition of scholaship - namely, that the social groups investigated in the name of 'subcultures' are subordinate, subaltern or subterranean” (GELDER e THORNTON, 1997, p. 04).
} 
como "estilos de vida". As subculturas acabam adquirindo essa característica de alteridade 5 .

O atributo definidor das 'subculturas', então, reside na maneira como a ênfase é colocada na distinção entre um grupo cultural/social particular e uma cultura/sociedade mais ampla. A ênfase é na variação de uma coletividade maior que é invariavelmente, mas não sem problemas, posicionada como normal, mediana e dominante. Subculturas, em outras palavras, são condenadas a e/ou desfrutarem uma consciência da 'alteridade' ou diferença' (GELDER e THORNTON, 1997, p.05).

As subculturas têm no estilo sua manifestação mais visível. "O estilo, quando manifestado através da vestimenta, do visual, dos sons, das performances, e etc, é um meio poderoso de dar ao grupo validação e coerência” (GELDER e THORNTON, 1997, p. 373). Dentro dessa mesma noção, podemos dizer que o estilo diz algo a respeito da subcultura, embora nem sempre seu conteúdo esteja claro. Além disso, aconteceram algumas mudanças nos seus eixos de análise.

Mais do que caracterizar diferenças culturais como 'resistências' à hierarquia ou às remotas dominações culturais de alguma classe dominante, as subculturas investigam as micro-estruturas de poder entalhadas nos desacordos culturais e debates que acontecem entre grupos associados mais intimamente ${ }^{7}$ (THORNTON, 1996, p. 163).

\footnotetext{
5 Daí também uma possível relação entre a Ficção Científica enquanto um gênero (seja ele literário ou cinematográfico) e as subculturas, nesse posicionamento e ênfase de apresentar o outro, os desviantes.

6 "The defining attribute of 'subcultures', then, lies with the way the accent is put on the distinction between a particular cultural/social group and the larger culture/society. The emphasis is on variance from a larger collectivity who are invariably, but not unproblematically, positioned as normal, average and dominant. Subcultures, in other words, are condemned to and/or enjoy a counciousness of 'otherness' or difference" (THORNTON, 1997, p.05).

7 "Rather than characterizing cultural differences as 'resistances' to hierarchy or to the remote cultural dominations of some ruling class, it investigates the micro-structures of power entailed in the cultural disagreements and debates that go on between more closely associated social groups (THORNTON, 1996, p. 163).
} 
Justamente nessa passagem da subcultura de resistência - da qual os estudos de Hebdige (1979) sobre o punk é pioneiro - à subcultura do capital simbólico subcultural (THORNTON, 1996) é que surge a discussão acerca da terminologia pós-subcultura (MUGGLETON, 2000; HODKINSON, 2002 e MUGGLETON e WEINZIERL, 2004) como substituta da subcultura caracterizada pela resistência.

\section{Do punk ao cyberpunk - um link entre o movimento literário e as manifestações sociológicas}

Não é nosso objetivo aprofundar essa discussão nesse momento, apenas apresentá-la como mais um dos pontos na rede de semelhanças e rupturas pelas quais passam os conceitos utilizados aqui, a fim de uma compreensão arque-genealógica do conceito de cyberpunk e de suas apresentações, que o originaram enquanto modo de ser e uma das formas estético-sociais da cibercultura $^{8}$. Dessa forma, apropriamo-nos do conceito de subcultura, construindo uma ponte entre o movimento literário cyberpunk e as manifestações sociais e estilísticas por ele influenciadas, com o objetivo particular de analisar o cyberpunk enquanto fusão de um subgênero da literatura de ficção-científica ${ }^{9}$ e das teorias da cibercultura, como uma apresentação material do imaginário tecnológico.

\footnotetext{
8 Os estudos mais recentes de subculturas já estão tratando das relações entre ela e a cibercultura, principalmente através das etnografias virtuais. Um exemplo disso é a pesquisa de Hodkinson que inclui uma etnografia virtual das subculturas (2002).

9 Em relação ao cyberpunk enquanto movimento literário da Ficção Científica, uma contextualização dentro da história da mesma e a presença constante dos elementos do romantismo gótico podem ser aprofundadas em AMARAL, Adriana. Espectros da ficção científica. A herança sobrenatural do gótico no cyberpunk. Revista Verso e Reverso, São Leopoldo, v. 38, ago. 2004. Disponível em: <http://www.versoereverso.unisinos.br/index.php? $\mathrm{e}=2 \& \mathrm{~s}=9 \& \mathrm{a}=15>$ Acesso em: 08 ago. 2004. Esse paper foi apresentado no XII Encontro da Compós, em São Bernardo do Campo, 2004.
} 
Um dado importante diz respeito aos estudos de 'subcultura' no Brasil ${ }^{10}$ e de sua inserção no campo da comunicação e da cibercultura. As pesquisas encontradas que lidam com esse tema (e foram em torno de seis) são todas em nível de dissertações de mestrado e são do campo da psicologia, da história e da sociologia. Na área da comunicação, até o momento há apenas o trabalho de mestrado de Cláudio Manuel Duarte de Souza (2003) ${ }^{11}$ sobre a cena da música eletrônica' ${ }^{12}$ enquanto uma subcultura. Não foi encontrada nenhuma tese de doutorado sobre o assunto. Esses pontos indicam que existe um campo a ser explorado nos estudos sobre subculturas no âmbito acadêmico brasileiro.

\subsection{Levantando a poeira dos subterrâneos - as subculturas juvenis do pós-guerra nos Estados Unidos e na Inglaterra.}

Nessa trajetória arqueológica é preciso reconstituir os primeiros e básicos acordes do punk enquanto uma subcultura juvenil que deixou seus rastros na ficção cyberpunk. Para tanto, é necessário que façamos uma pequena digressão espaço-temporal e voltemos brevemente a uma apresentação das primeiras subculturas juvenis do século 20.

Brake (1980, p. 10) enfatiza a importância da urbanização como um dos pontos centrais no processo de subculturização da juventude. Geralmente, as subculturas fazem parte da área boêmia da vida metropolitana. O autor aponta que no período pós Segunda Guerra Mundial, em meio às transformações comportamentais (como por exemplo, a entrada das mulheres no mercado de trabalho) e tecnológicas as subculturas começaram a surgir,

\footnotetext{
${ }^{10}$ A fonte desses dados foi o Banco de Teses e Dissertações da CAPES, disponível online em http://www.capes.gov.br/capes/portal/conteudo/10/Banco Teses.htm, acessado em 20/04/2005.
}

${ }^{11}$ SOUZA, Cláudio Manuel Duarte. Música Eletrônica e Cibercultura: idéias em torno da sociabilidade, da comunicação em redes telemáticas e cultura do DJ. Dissertação de Mestrado, UFBA, 01/07/2003. 164p.

12 Também destacamos os trabalhos de SÁ, Simone Pereira de (2003b e 2004) que fazem uma aproximação sutil com o tema, também o relacionando com a cena da música eletrônica no Brasil. 
muito devido a um sentimento de revolta, pois a subcultura reflete os problemas específicos de uma geração particular. Em sua pesquisa, Brake (1980, p. 23) mostra que os estudo sobre a juventude normalmente podem ser divididos em 4 (quatro) grandes áreas:

1) juventude "respeitável” - são os jovens que não estão envolvidos em nenhuma cultura adolescente, talvez apenas em modismos, mas não necessariamente em estilos de vida. São os jovens que vivem a cultura mainstream. Esse grupo é visto pelas subculturas desviantes como conformistas, sendo uma referência negativa para esses; 2) juventude delinqüente - normalmente relacionada com a questão da classe social. São os jovens que estão envolvidos com violência (física e sexual) e atividades ilegais como drogas, crimes, delitos, etc; 3) rebeldes culturais - é o grupo que tende a estar envolvido nas tradições boêmias e nas manifestações culturais. Tendem a ser classe-média e a possuir educação formal, em oposição ao grupo anterior que tende a ser da classe trabalhadora. Os rebeldes culturais "estão nas periferias do mundo artístico-literário, sendo aderentes a isto mais do que artistas" (BRAKE, 1980, p. 23); 4) juventude politicamente militante - são grupos específicos envolvidos com as mais variadas formas de fazer política. Pertencem a diferentes grupos e associações. É importante ressaltar que essas tipologias misturam-se entre si, influenciando uma à outra, sendo bastante permeáveis e sem muitas regras fixas, em constante transformação. O caso do punk, por exemplo, agrega um pouco de cada um dessas tendências.

A partir dos anos 90, diversos teóricos retrabalharam o conceito de subcultura em direção a uma pós-subcultura ${ }^{13}$, na qual as classes sociais dentro das subculturas já não se apresentam de forma tão fixa e rígida, muitas vezes sequer sendo importante para a questão do pertencimento ao grupo. A pós-subcultura (MUGGLETON e WEINZIERL, 2003) está assim, muito mais ligada à identificação e ao estilo do que com um caráter ideológico e de

13 Ver MUGGLETON, David, WEINZIERL, Rupert (ed.). The post-subcultures reader. New York: Berg, 2003. 
resistência que era visto nas análises do final dos anos 70 e década de 80 , particularmente no caso da cena punk, que foi a primeira subcultura juvenil reconhecida por ter uma importância ideológica ${ }^{14}$, além de uma dimensão estética e, por isso, de certa forma "legitimada" pela comunidade acadêmica. A transição da subcultura em pós-subcultura é marcada pela aceitação de que a subcultura não é necessariamente de cunho ideológico, mas que o pertencimento acontece, em muitos casos, através do estilo estético. Esse estilo estético das subculturas pode ser de comparado ao neotribalismo maffesoliniano no qual a estética torna-se o laço afetivo de ligação entre os indivíduos é a principal característica das sociedades contemporâneas.

Brake (1980) faz um apanhado geral das primeiras subculturas inglesas e norte-americanas. As subculturas citadas abaixo são da ordem da rebeldia cultural, embora muitas vezes haja um envolvimento ou períodos em que as subsubculturas envolvem-se com a delinqüência (drogas, pequenos crimes, etc), com a militância política (por exemplo, no caso dos hippies com seus protestos antibélicos ou organizações coletivas e do punk e sua relação com o anarquismo), assim como uma penetração da própria juventude "respeitável", uma vez que:

Em uma subcultura com afiliações literárias e artísticas, existem membros centrais no centro da cultura, na maioria das vezes artistas criativos, mas há seguidores e membros periféricos que podem adotar o estilo de vida ou a aparência e podem ou não ser percebidos como membros "verdadeiros"15 (BRAKE, 1980, p. 72).

Esse parece ser também o caso da subcultura cyberpunk em sua tradição de artistas undergrounds. Mais uma vez a subcultura apresenta-se no foco de atuação de distintas forças, tanto internas (as lutas e sucessões entre os

\footnotetext{
14 Os estudos de Dick Hebdige sobre mods, punks e skinheads $(1975,1979,1981)$ contribuíram para apontar os significados ideológicos dessas diferentes subculturas.

15 "In a subculture with a literary and artistic affiliations, there are core members at the centre of the culture, often creative artists, but followers and peripheral members who may adopt the lifestyle or appearence, and who may or may not be perceived as "real" members" (BRAKE, 1980, p. 72).
} 
membros desdobrando-se em sub-subculturas; assim como ideológicas versus estéticas) quanto externas (a luta da subcultura com a cultura dominante, mainstream) e inter-relacionadas (as forças e disputas pelo poder entre as diferentes subculturas como, por exemplo, o caso da famosa rivalidade entre mods e rockers principalmente no ano de 1964).

Segundo Brake (1980), as principais subculturas entre os anos 40 e os 70 basicamente foram: 
Revista da Associação Nacional dos

Programas de Pós-Graduação em Comunicação

\section{(e) compós}

\begin{tabular}{|c|c|c|c|c|}
\hline Subcultura & Período & Características & Estilo & Sub-subculturas \\
\hline $\begin{array}{l}\text { Teddy } \\
\text { Boys }\end{array}$ & $\begin{array}{l}\text { Fim dos } \\
\text { anos 40/ } \\
\text { Início dos } \\
50\end{array}$ & $\begin{array}{l}\text { Celebração do macho, da } \\
\text { masculinidade em geral. } \\
\text { Ícones: James Dean, Marlon } \\
\text { Brando e Elvis Presley. }\end{array}$ & $\begin{array}{l}\text { Algumas doses de } \\
\text { dandismo adaptadas ao } \\
\text { culto ao corpo } \\
\text { masculino.Vestiam-se com } \\
\text { jaquetas de couro, óculos } \\
\text { escuros, jeans. }\end{array}$ & $\begin{array}{l}\text { Mais tarde transformaram-se em } \\
\text { rockers. }\end{array}$ \\
\hline Beats & $\begin{array}{l}\text { Anos } 50 \text { e } \\
\text { início dos } \\
\text { anos } 60\end{array}$ & $\begin{array}{l}\text { Intelectuais de classe média } \\
\text { que foram influenciados } \\
\text { pelo existencialismo } \\
\text { enquanto corrente filosófica. } \\
\text { Individualismo, misticismo } \\
\text { oriental, situacionistas } \\
\text { franceses, dadaísmo, psico- } \\
\text { análise, surrealismo, } \\
\text { espontaneidade, literatura e } \\
\text { drogas formavam o coquetel } \\
\text { de características dos } \\
\text { artistas beats em sua } \\
\text { subcultura. }\end{array}$ & $\begin{array}{l}\text { "Como em todas as } \\
\text { subculturas boêmias, } \\
\text { existiam os núcleos } \\
\text { intelectuais-artísticos que } \\
\text { eram o centro de um } \\
\text { movimento social mais } \\
\text { expressivo, que gerava } \\
\text { seguidores de um estilo de } \\
\text { vida simbolizado pela } \\
\text { filosofia dos líderes, na } \\
\text { intelligentsia e nas artes. O } \\
\text { existencialismo se tornou } \\
\text { a base de um estilo de vida } \\
\text { entre os estudantes e } \\
\text { boêmios, e o seu estilo de } \\
\text { camisas de gola alta e } \\
\text { jeans azul foi espalhado } \\
\text { pelos expatriados } \\
\text { parisienses para outras } \\
\text { partes da Europa e da } \\
\text { América do Norte." } \\
\text { (Brake, 198o, p. 9o) }\end{array}$ & $\begin{array}{l}\text { Hipsters - os que eram membros da } \\
\text { classe trabalhadora e que, mais tarde, } \\
\text { aderiram ao misticismo oriental e a um } \\
\text { estilo de vida mais "livre" e natural. } \\
\text { Acabaram originando os hippies, } \\
\text { quando de seu deslocamento para São } \\
\text { Francisco. }\end{array}$ \\
\hline Mods & $\begin{array}{l}\text { Metade dos } \\
60\end{array}$ & $\begin{array}{l}\text { Surgiram na "swinging } \\
\text { London".Os mods eram o } \\
\text { símbolo do afluente } \\
\text { consumo adolescente e a sua } \\
\text { elegância acabou se } \\
\text { transformando em ameaça. }\end{array}$ & $\begin{array}{l}\text { "A prática do cool” } \\
\text { Possuíam uma distância } \\
\text { sofisticada. } \\
\text { Dandismo }\end{array}$ & $\begin{array}{l}4 \text { Tipos: } \\
\text { Art high camp mods - "uma nova } \\
\text { forma de imaginário masculino". } \\
\text { Desajustamento da masculinidade, } \\
\text { garotos usando maquiagem. Mais } \\
\text { tarde desdobrou-se nos }\end{array}$ \\
\hline
\end{tabular}




\begin{tabular}{|c|c|c|c|c|}
\hline & & $\begin{array}{l}\text { As fronteiras sexuais eram } \\
\text { menos distintas no mundo } \\
\text { mod, com garotas de cabelos } \\
\text { curtos, corpos retos e rostos } \\
\text { inexpressivos, enquanto os } \\
\text { garotos eram } \\
\text { elaboradamente espertos e } \\
\text { não masculinos. }\end{array}$ & $\begin{array}{l}\text { Ternos italianos } \\
\text { Droga: heroína } \\
\text { Nos EUA, adotam o jazz } \\
\text { como música e na } \\
\text { Inglaterra mais tarde } \\
\text { adotam o rock. }\end{array}$ & $\begin{array}{l}\text { glamrockers/glitter. } \\
\text { Mainstream Mods - também } \\
\text { chamados Smooth Mods, adotaram } \\
\text { o rhythm and blues, compensam a vida } \\
\text { operária pelo lazer à noite, com } \\
\text { glamour e fantasia. Uso de ternos, } \\
\text { calças justas e sapatos pontudos. } \\
\text { Utilizavam uma mistura de pílulas } \\
\text { soníferas com bebidas como droga. } \\
\text { Alguns desses elementos são } \\
\text { apropriados pela disco music nos anos } \\
\text { 70. } \\
\text { Scooter Boys - Eram mods lque } \\
\text { utilizavam as motos italianas scooter e } \\
\text { usavam anoraks (jaquetas curtas estilo } \\
\text { parka com capuz e impermeáveis), } \\
\text { jeans amplos e sapatos de lona. } \\
\text { Hard Mods - Usavam jeans e } \\
\text { coturnos e mais tarde, muitos } \\
\text { acabaram tornando-se skinheads }\end{array}$ \\
\hline Rockers & $\begin{array}{l}\text { Metade dos } \\
\text { anos 6o } \\
\text { (paralelo }\end{array}$ & $\begin{array}{l}\text { São um tipo de cowboy } \\
\text { motorizado, solitários e } \\
\text { outsiders, atitude anti- }\end{array}$ & $\begin{array}{l}\text { Idéia do macho andarilho } \\
\text { livre dos laços tradicionais } \\
\text { domésticos (casamento) e }\end{array}$ & $\begin{array}{l}\text { Bikers - sudvidem-se em Wild Ones } \\
\text { (Selvagens) e em Hell's Angels. }\end{array}$ \\
\hline
\end{tabular}


Revista da Associação Nacional dos

\section{(e) compós}

\begin{tabular}{|c|c|c|c|c|}
\hline & aos mods) & $\begin{array}{l}\text { autoridade. Seu lema era } \\
\text { viver o presente. Ligados aos } \\
\text { carros e às motos como } \\
\text { forma de controle do corpo. } \\
\text { Violência e sexualidade. }\end{array}$ & $\begin{array}{l}\text { de respeitabilidade. } \\
\text { Os rockers adotaram o } \\
\text { rockabilly como música e o } \\
\text { speed como droga. } \\
\text { A dança era de um estilo } \\
\text { mais individual. O visual } \\
\text { era composto por topetes } \\
\text { cheios de gel, jaquetas de } \\
\text { couro pretas e jeans. }\end{array}$ & $\begin{array}{l}\text { Culto às motos. } \\
\text { Greasers } \mathbf{1 6} \text { - Idêntico aos bikers } \\
\text { (motoqueiros),mas com ênfase nos } \\
\text { carros. Ao findar dos anos 6o, uniam a } \\
\text { imagem agressiva dos rockers à } \\
\text { imagem clean dos mods. }\end{array}$ \\
\hline $\begin{array}{l}\text { Skinhead } \\
\text { s }\end{array}$ & $\begin{array}{l}\text { Final dos } \\
\text { anos } 60\end{array}$ & $\begin{array}{l}\text { Evoluíram a partir dos hard } \\
\text { mods. Nessa fase, possuíam } \\
\text { uma estreita relação com os } \\
\text { torcedores de times } \\
\text { (hooligans). Mantêm os } \\
\text { valores conservadores da } \\
\text { classe trabalhadora. Muito } \\
\text { devido à falta de emprego e } \\
\text { às políticas da sociedade } \\
\text { inglesa para com os } \\
\text { imigrantes (em especial os } \\
\text { asiáticos), os gays e os } \\
\text { hippies (pela questão da } \\
\text { masculinidade, pois os } \\
\text { cabelos longos dos hippies } \\
\text { agrediam o valor de }\end{array}$ & $\begin{array}{l}\text { Usavam jeans com barras } \\
\text { dobradas, botas } \\
\text { industriais estilo Doc } \\
\text { Marten, braceletes e } \\
\text { cabelos raspados (a } \\
\text { princípio usavam o corte } \\
\text { suedehead). } \\
\text { É irônico e, de certa } \\
\text { forma, um contrasenso, o } \\
\text { fato de que no princípio, } \\
\text { os skinheads adotaram } \\
\text { como sua, a música negra } \\
\text { em geral o bluebeat, o } \\
\text { soul, o reggae e o ska. Isso } \\
\text { apenas remete à questão }\end{array}$ & $\begin{array}{l}\text { Geralmente os skinheads dividem-se } \\
\text { nos subgrupos White Power (de } \\
\text { afiliação nazista) e Oi! (os que não } \\
\text { possuem afiliação fascista) }\end{array}$ \\
\hline
\end{tabular}

${ }^{16}$ O filme Grease - Nos tempos da brilhantina (Grease, Randal Kleiser, Estados Unidos, 1978) a presenta em forma de comédia romântica/musical um pouco dessa estética através do personagem Danny Zuko (John Travolta) e sua gangue. 
Revista da Associação Nacional dos

\section{e compós}

\begin{tabular}{|c|c|c|c|c|}
\hline & & $\begin{array}{l}\text { masculino dos skins). Os } \\
\text { skinheads começaram junto } \\
\text { com o movimento punk, mas } \\
\text { tornaram-se inimigos e } \\
\text { contrários politicamente. } \\
\text { Mais tarde (entre 78-79) é } \\
\text { que começa a adoção do } \\
\text { nazi-fascismo por parte dos } \\
\text { skins, em sua associação } \\
\text { com o partido National } \\
\text { Front, contudo, existem } \\
\text { skinheads que não são } \\
\text { racistas. }\end{array}$ & $\begin{array}{l}\text { da origem operária do } \\
\text { movimento. Apenas nos } \\
\text { anos 70, eles adotaram o } \\
\text { hardcore como música, } \\
\text { devido à aproximação em } \\
\text { determinados pontos com } \\
\text { a estética punk. (O' HARA, } \\
\text { 1999) }\end{array}$ & \\
\hline Hippies & Anos 60/70 & $\begin{array}{l}\text { Subcultura boêmia e } \\
\text { estudantil em sua maioria, } \\
\text { envolvendo um estilo de } \\
\text { vida rebelde, artístico- } \\
\text { literário. Adotam um certo } \\
\text { gnosticismo romântico. } \\
\text { Originaram também muitos } \\
\text { dos movimentos sociais } \\
\text { como o feminismo e as } \\
\text { militâncias políticas. }\end{array}$ & $\begin{array}{l}\text { São inimigos da } \\
\text { tecnocracia.Experimentaç } \\
\text { ão com drogas (LSD, } \\
\text { mescalina, maconha, } \\
\text { peyote, etc)Cabelos longos } \\
\text { para homens e mulheres e } \\
\text { barbas longas para } \\
\text { homens. Desenvolvimento } \\
\text { da imprensa } \\
\text { underground.Adotam o } \\
\text { folk rock e o rock como } \\
\text { forma de protesto. }\end{array}$ & $\begin{array}{l}\text { Freaks - eram os burgueses } \\
\text { alternativos que possuíam um } \\
\text { conhecimento específico, mas que } \\
\text { pareciam estranhos aos olhos da } \\
\text { sociedade por terem abandonado suas } \\
\text { vidas comuns. } \\
\text { Heads - muitas vezes acabavam } \\
\text { envolvendo-se em furtos para manter } \\
\text { o vício das drogas }\end{array}$ \\
\hline
\end{tabular}


Revista da Associação Nacional dos

Programas de Pós-Graduação em Comunicação

\section{e compós}

\begin{tabular}{|c|c|c|c|c|}
\hline $\begin{array}{l}\text { Glamrock } \\
\text { / } \\
\text { Glitter }^{17}\end{array}$ & $\begin{array}{l}\text { Início dos } \\
70\end{array}$ & $\begin{array}{l}\text { Reminiscentes dos mods } \\
\text { artísticos na Inglaterra, } \\
\text { buscam um efeito estético na } \\
\text { sociedade }^{18} \text {. } \\
\text { Surgem em um momento de } \\
\text { aburguesamento da } \\
\text { sociedade e do aparecimento } \\
\text { de áreas de lazer específicas } \\
\text { para a juventude. }\end{array}$ & $\begin{array}{l}\text { Salto alto, maquiagem } \\
\text { elaborada e roupas } \\
\text { extravagantes para } \\
\text { homens e mulheres. Culto } \\
\text { à androginia e ao } \\
\text { bissexualismo. } \\
\text { Baseiam-se nas imagens } \\
\text { de decadência da Berlim } \\
\text { dos anos 3o e das } \\
\text { subculturas gays de New } \\
\text { York City. } \\
\text { Música: rock de Marc } \\
\text { Bolan, T-REx, Gary } \\
\text { Glitter, Lou Reed e David } \\
\text { Bowie (que através de seu } \\
\text { personagem alienígena } \\
\text { rockstar Ziggy Stardust } \\
\text { criou uma imagem do rock } \\
\text { como conceito) }\end{array}$ & $\begin{array}{l}\text { Observação: } \\
\text { o glam/glitter inspirou as subculturas } \\
\text { pós-punk como a New Wave e o } \\
\text { Gótico/Dark, assim como a cultura } \\
\text { industrial/ eletrônica. Todas essas } \\
\text { subculturas se apropriaram tanto de } \\
\text { elementos do próprio punk como do } \\
\text { glam/glitter em sua constituição. }\end{array}$ \\
\hline Punk & $\begin{array}{l}\text { Metade para } \\
\text { o fim dos } \\
\text { anos } 70\end{array}$ & $\begin{array}{l}\text { Londres e NYC detêm a } \\
\text { criação dessa subcultura.É a } \\
\text { primeira subcultura que é ao } \\
\text { mesmo tempo boêmia e } \\
\text { pertencente à classe }\end{array}$ & $\begin{array}{l}\text { Cabelos espetados, } \\
\text { pintados de cores vivas, } \\
\text { roupas baseadas em } \\
\text { BDSM e fetiches sexuais } \\
\text { ou roupas colegiais velhas. }\end{array}$ & $\begin{array}{l}\text { Anarco Punks - ligados ao } \\
\text { anarquismo }\end{array}$ \\
\hline
\end{tabular}

${ }_{17}$ Glitter, "brilho", e Glam, de "glamour".

18 A respeito do imaginário desse período pode ser conferido no filme Velvet Goldmine (Velvet Goldmine, Todd Haynes, Inglaterra/EUA, 1998) que mostra a cena do glitter/glamrock inglês e novaiorquino. 
Revista da Associação Nacional dos

Programas de Pós-Graduação em Comunicação

\section{e compós}

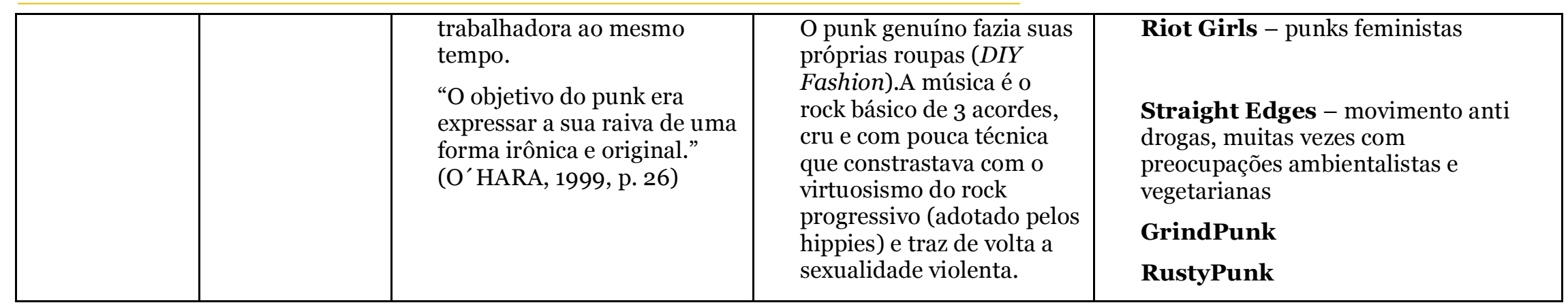




\subsection{Pós-punk - O crepúsculo do punk e o surgimento do cyberpunk}

Assim como os hippies nos anos 60, o punk foi um divisor de águas dentro das subculturas da ordem juvenil de rebeldia cultural (BRAKE, 1980), tanto que o período que seguiu ao punk ${ }^{19}$ ficou conhecido como o pós-punk. Em nosso resgate dos elementos deixados pelo punk no surgimento do cenário pós-punk, percebe-se que o principal vestígio que permanece em uma subcultura para a outra é a chamada atitude ou espírito D.I.Y. (Do It Yourself - Faça Você Mesmo) embora utilizado das mais diferentes maneiras (principalmente em relação às tecnologias), o Faça Você Mesmo continuou presente como um conceito central do underground. Outra observação pertinente é que o chamado pós-punk parece estar muito mais facilmente identificado com os diferentes estilos musicais que $o$ constituem do que com as subculturas propriamente ditas. Os estilos musicais e a estética que os envolvem aparecem assim, como fatores determinantes ao pertencimento a determinado grupo social.

Muito dessa influência vem do aumento de importância e a disseminação da imprensa musical especializada, com destaque especial para os semanários e revistas britânicas e norte-americanas de música (podemos citar como exemplo o New Musical Express e a revista Spin) que, durante esse período, cresceram muito, influenciando no consumo de novas bandas e artistas e expondo artistas antes undergrounds ou "alternativos" a um público muito maior. Em termos musicais, isso acontece, principalmente porque o punk permitiu que o rock voltasse ao seu estado básico e de agente de rebeldia que o caracterizavam antes de sua incorporação ao sistema comercial. Como em todas as subculturas anteriores, inicialmente o pós-punk foi ignorado pelos críticos. Normalmente o foco dos documentários e das retrospectivas de televisão sobre a história do rock são os anos do punk, devido a toda transformação estética que ele trouxe, tanto à música quanto à moda e ao comportamento juvenil como um todo.

\footnotetext{
19 Para um melhor entendimento dessa trajetória da incorporação do punk pelo cyberpunk e os seus desdobramentos na cultura hacker e na cultura rivethead (inudstrial) ver AMARAL, Adriana. Visões obscuras do underground: Hackers e Rivetheads - o cyberpunk como subcultura híbrida, publicada em 404nOt Found, n.47, julho de 2005, disponível em <http://www.facom.ufba.br/ciberpesquisa/404nOtFound/404 47.htm>.
} 
Chegamos então aos anos 2000, onde as subculturas estão cada vez mais subdivididas e multifacetadas, sendo que, muitas vezes existe uma sinergia de trocas, em que alguns participantes de uma subcultura também participam de outra. Assim, podemos traçar algumas conexões entre a imagem literária/visual dos cyberpunks e o que se vê nas ruas, na gênese e na constituição da subcultura cyberpunk, enquanto uma Weltanschauung, uma espécie de modo de ser na cibercultura, principalmente em seus aspectos estéticos na relação entre moda e tecnologia.

\section{O estilo do cyberpunk - hibridismo e trocas entre as subculturas.}

Vamos fazer algumas observações de como se configura o estilo cyberpunk, a partir dos três elementos que o definem segundo Brake (1980): imagem, conduta e dialeto. 


\section{Estilo}

Amor

A

\begin{tabular}{l|l} 
& gays, bissexuais, lésbicas, transgêneros. \\
Artes & O cyberpunk inspirou muitos artistas, principalmente na utilização
\end{tabular} de novas mídias como suporte da arte contemporânea. Alguns exemplos podem ser vistos nas obras de Kabir Fernandez,

Cyberpunk Art Gallery, disponível em

http://www.geocities.com/SiliconValley/Port/2045/photos/art.ht $\mathrm{ml}$

Ou no portfolio virtual do artista Misery em http://misery.subnet.at/eyedentify/index.html

Atitude Cyberpunk é um jeito de pensar, uma visão de mundo particular, mas isso não quer dizer que seja seguido à risca feito uma espécie de bíblia. A maior parte dessas atitudes vêm da ética hacker ou da filosofia punk. De acordo com a Mondo 200o, são elas: O campo de batalha é a mente das pessoas; o mundo está dividido em milhões de subculturas; os domínios da informação gerada por computador são as próximas fronteiras; as mega-corporações são os novos governantes; a vida pode ser melhor através da química; pequenos grupos podem ameaçar o poder sobre os governantes, corporações,
Relação com quais subculturas

No sentido do fetiche das relações sexuais homem e máquina, ela é uma constante na subcultura otaku com seu voyeurismo e suas fantasias de humanos fazendo sexo com televisores e computadores.

Para um lado mais carnal e menos virtual do sexo, o punk e as subculturas do pós-punk ampliaram as discussões e questionamentos de regras sociais com sua estética de pluralidade sexual e sadomasoquismo.

De uma certa maneira, todas as subculturas do século 20 (conforme vimos nesse capítulo) possuem esse tipo de atitude. No entanto, no caso do punk elas ficam mais visíveis devido ao D.I.Y. 


\begin{tabular}{|c|c|c|}
\hline & $\begin{array}{l}\text { etc; a cultura do computador é expressa através da arte, da música, } \\
\text { das comunidades virtuais, das subculturas das ruas e as pessoas } \\
\text { não tem mais vergonha de assumir o papel que o computador } \\
\text { desempenha em suas vidas dentro das subculturas; estamos nos } \\
\text { tornando cyborgs, pois as tecnologias estão se tornando cada vez } \\
\text { menores e mais próximas em nosso cotidiano e em breve se } \\
\text { fundirão conosco. Os cyberpunks defendem a liberdade da } \\
\text { informação, o anti-autoritarismo,o enfrentamento do poder, a } \\
\text { devolução do "ruído" como feedback à sociedade e o faça você } \\
\text { mesmo. }\end{array}$ & \\
\hline Drogas & $\begin{array}{l}\text { O uso de drogas (sintéticas ou naturais) é uma constante no } \\
\text { ambiente tanto da FC cyberpunk quanto das subculturas. A maior } \\
\text { parte delas são ilegais na Inglaterra e nos Estados Unidos. A } \\
\text { listagem abaixo é das drogas mais consumidas no ambiente de } \\
\text { raves/clubs }{ }^{20} \text {, assim como as que mais aparecem nas novelas } \\
\text { cyberpunks. Elas podem ser de três tipos: 1) as que produzem } \\
\text { efeito de aceleração mental - anfetamina (speed), metanfetamina } \\
\text { (ice ou meth), cocaína, crack, efedrina, dexedrina (dexys), Cat e } \\
\text { Poppers; 2) as que produzem relaxamento - DXM, GBH, } \\
\text { Temazepan; 3) as que produzem estados alterados de consciência } \\
\text { - 2CB, maconha, MDMA (Ecstasy, XTC, E), Ketamine (Special K), } \\
\text { LSD, cogumelos. }\end{array}$ & $\begin{array}{l}\text { Desde o princípio, as drogas aparecem relacionadas às } \\
\text { diferentes subculturas, cada uma com sua tendência } \\
\text { específica. No entanto, o ideal é não generalizar, pois nem } \\
\text { todos os participantes das subculturas utilizam drogas. Assim } \\
\text { como muitas pessoas que não participam de nenhuma } \\
\text { subcultura as utilizam. }\end{array}$ \\
\hline HQs e & Animações: Akira, Ghost in the Shell 1 e 2, Aeon flux, American & Otakus, hackers. \\
\hline
\end{tabular}

${ }^{20}$ Informações obtidas em http://project.cyberpunk.ru/idb/cyberpunkdrugs.html 


\begin{tabular}{|c|c|c|}
\hline Animações & $\begin{array}{l}\text { cyborg, Tetsuo } 1 \text { e } 2 \text {,etc. } \\
\text { HQs: Batmam Digital Justice, Judge Dredd }\end{array}$ & \\
\hline Leituras & $\begin{array}{l}\text { Autores da geração cyberpunk como Gibson, Cadigan, Sterling, } \\
\text { Bethke, Stephenson, Shirley, Shiner e outros. Também outros } \\
\text { autores de FC em geral e horror e fantasia. Além disso, livros sobre } \\
\text { a cultura hacker. }\end{array}$ & \\
\hline Moda & $\begin{array}{l}\text { Não há um estilo exato, mas tendem a vestir-se dando a impressão } \\
\text { de um pouco de futurismo. Usualmente com cores escuras ou todo } \\
\text { de preto. Pedaços de metal ou chips de computador também fazem } \\
\text { parte do visual, que pode incluir materiais sintéticos como vinil, } \\
\text { lycra e borracha. Embora o couro natural seja valorizado e } \\
\text { utilizado em jaquetas, casacos e botas. Extensões de cabelos } \\
\text { também são comuns. A moda também atinge o design das } \\
\text { tecnologias como no caso dos notebooks, palmtops, celulares, mp3 } \\
\text { players etc. }\end{array}$ & Punk, Gótico, Clubber /Raver, Industrial, Hackers \\
\hline Música & $\begin{array}{l}\text { A música cyberpunk é indefinível, pois abrange uma série muito } \\
\text { grande de estilos e subestilos. Além disso, não há um consenso a } \\
\text { respeito desse assunto.Tanto o punk rock, quanto o hardcore, o }\end{array}$ & $\begin{array}{l}\text { O punk, o gótico, o clubber/raver e o industrial parecem ser } \\
\text { as subculturas com mais ligação musical com o cyberpunk, } \\
\text { em específico bandas industriais como NIN, Prodigy, EBM }\end{array}$ \\
\hline
\end{tabular}




\begin{tabular}{|c|c|c|}
\hline & $\begin{array}{l}\text { metal, o gótico e o techno (que também lida com as questões do } \\
\text { sintético versus analógico) parecem fazer parte do cenário } \\
\text { cyberpunk. No entanto, é a chamada música industrial que parece } \\
\text { caracterizar melhor a sonoridade cyberpunk através de bandas que } \\
\text { misturem o rock ou o punk rock ou metal com sons eletrônicos e } \\
\text { sombrios. E assim como alguns autores (Sterling, Cadigan, Gibson, } \\
\text { Shirley) citam bandas ou músicas, também as bandas citam os } \\
\text { autores ou fazem referências às temáticas cyberpunks. }\end{array}$ & $\begin{array}{l}\text { como Front } 242 \text { e tecno como Chemical Brothers e Sven } \\
\text { Vath. Um outro exemplo é a banda industrial /powernoise } \\
\text { norte-americana My life with the thrill kill kult que possui } \\
\text { músicas como "After the flesh" (Depois da carne) falando } \\
\text { sobre a dicotomia corpo e mente em relação à tecnologia. } \\
\text { Alguns artistas considerados mais mainstream como U2 e } \\
\text { Primal Scream também já utilizaram a temática cyberpunk } \\
\text { em seus trabalhos. E o ex-punk Billy Idol lançou em } 1993 \text { um } \\
\text { álbum chamado Cyberpunk que causou muita polêmica, } \\
\text { embora tenha sido um fracasso de vendas. }\end{array}$ \\
\hline Televisão & $\begin{array}{l}\text { Alguns programas de TV e documentários incorporaram a estética } \\
\text { cyberpunk e/ou falaram sobre o fenômeno. Eis alguns exemplos: } \\
\text { Max Headroom - } 20 \text { minutos no futuro (série de TV lançada na } \\
\text { Inglaterra em } 85 \text { e depois produzida nos EUA em 87); Kill Switch e } \\
\text { First Person Shooter (dois episódios cyberpunks em Arquivo X } \\
\text { escritos por William Gibson e Tom Maddox em } 1998 \text { e em } 2000 \\
\text { respectivamente); Wild Palms (mini-série de 1993 dirigida por } \\
\text { Oliver Stone), Cyberpunk, documentário de 1990,da Intercon } \\
\text { Productions documentary. }\end{array}$ & \\
\hline
\end{tabular}


A partir desse quadro, observou-se o estilo da subcultura cyberpunk em suas mixagens, assemblages, transformações, reaproveitamentos, citações e hibridizações, originadas a partir de subculturas que lhe são anteriores e ao mesmo tempo pertencentes às formações estéticas e contraculturais da cultura tecnológica, com suas preocupações entre a mistura de analógico e sintético; humano e não-humano, eletrônico e acústico. Percebemos também a disseminação do cyberpunk através de outras mídias como o cinema, os quadrinhos, música, moda, os games, etc, elementos fundamentais para a formação de uma cultura própria feita de jargões, gírias, e elementos visuais. Apontamos assim, apenas algumas das forças e dos valores que pularam das páginas da ficção científica, na tênue linha entre a tecnologia de ponta e as subjetividades urbanas, um fenômeno característico da cibercultura.

\section{Referências Bibliográficas:}

AMARAL, Adriana. Espectros da ficção científica. A herança sobrenatural do gótico no cyberpunk. Revista Verso e Reverso, São Leopoldo, v. 38, ago. 2004. Disponível em: $<$ http://www.versoereverso.unisinos.br/index.php?e=2\&s=9\&a=15> Acesso em: 08 ago. 2004.

AMARAL, Adriana. Visões Perigosas: uma arque-genealogia do cyberpunk - do romantismo gótico às subculturas. Comunicação e cibercultura em Philip K. Dick. Porto Alegre: PUCRS, 2005. Tese (Doutorado em Comunicação Social), Pontifícia Universidade Católica do Rio Grande do Sul, 2005.

AMARAL, Adriana. Visões obscuras do underground: Hackers e Rivetheads - o cyberpunk como subcultura híbrida, publicada em 404nOt Found, n.47, julho de 2005, disponível em <http://www.facom.ufba.br/ciberpesquisa/404nOtFound/404_47.htm>

BANCO DE TESES E DISSERTAÇÕES DA CAPES/CNPq. Disponível em: $<$ http://www.capes.gov.br/capes/portal/conteudo/10/Banco_Teses.htm $>$ Acesso em: mar. 2005.

BRAKE, Mike. The sociology of youth culture and youth subcultures. London: Routledge, 1980.

CYBERPUNK INFORMATION DATABASE. Disponível em: $<$ http://project.cyberpunk.ru/idb > Acesso em mar. 2005. 
GELDER, Ken, THORNTON, Sarah (ed.). The subcultures reader. London: routledge, 1997.

HEBDIGE, Dick. Subculture: the meaning of style. London: Methuen, 1979.

HEBDIGE, Dick. Posing... threats, striking... poses: youth, surveillance and display. In: GELDER, Ken, THORNTON, Sarah (ed.). The subcultures reader. London: Routledge, 1997.

HODKINSON, Paul. Goth: identity, style, and subculture. New York: Berg, 2002.

MUGGLETON, David, WEINZIERL, Rupert (ed.). The post-subcultures reader. New York: Berg, 2003.

SÁ, Simone Pereira de. Música eletrônica e tecnologia: reconfigurando a discotecagem. In: LEMOS e CUNHA (orgs). Olhares sobre a cibercultura. Porto Alegre: sulina, 2003b.

SÁ, Simone Pereira de, MARCHI, Leonardo de. Não basta ser DJ. Tem que ser underground! Sobre coletivos e comunidades virtuais de música eletrônica no Brasil. GT de Tecnologias Informacionais de Comunicação e Sociedade no XIII Encontro da COMPÓS. Disponível em: <www.compos.org.br> Acesso em: 20 mai. 2004.

SOUZA, Cláudio Manuel Duarte. Música Eletrônica e Cibercultura: idéias em torno da sociabilidade, da comunicação em redes telemáticas e cultura do DJ. Dissertação de Mestrado, UFBA, 01/o7/2003. 164p.

THORNTON, Sarah. Club cultures. Music, media and subcultural capital. Connecticut: Wesleyan University Press, 1996. 